\title{
New technique of dissection of internal mammary vessels for breast reconstruction
}

\author{
Arthur Ismagilov ${ }^{1,2,3}$, Anna Vanesyan ${ }^{3}$, Irina Ovchinnikova ${ }^{3}$, Airat Khamitov ${ }^{2,3}$, George Basiashvili ${ }^{2,3}$, \\ Sergei Zinchenko ${ }^{1,2,3}$ \\ ${ }^{1}$ Department of Surgery, Kazan Federal University, Kazan, Russia; ${ }^{2}$ Department of Plastic Surgery, Kazan State Medical Academy, Kazan, \\ Russia; ${ }^{3}$ Department of Breast Surgery, Regional Clinical Oncological Center of Tatarstan, Kazan, Russia \\ Contributions: (I) Conception and design: A Ismagilov, S Zinchenko; (II) Administrative support: A Ismagilov, I Ovchinnikova; (III) Provision of study \\ materials or patients: A Ismagilov, A Vanesyan, A Khamitov; (IV) Collection and assembly of data: All authors; (V) Data analysis and interpretation: A \\ Vanesyan, G Basiashvili; (VI) Manuscript writing: All authors; (VII) Final approval of manuscript: All authors. \\ Correspondence to: Anna Vanesyan, MD, PhD. Regional Clinical Oncological Center of Tatarstan, Kazan, Russia. Email: anna_vanesyan@yahoo.com.
}

\begin{abstract}
Background Although internal mammary vessels are considered the best recipients for free flap breast reconstruction, they present the notable drawback of limited accessibility. The aim of this study was to develop a minimally invasive surgical technique for the dissection of internal mammary vessels as recipients for breast reconstruction.
\end{abstract}

Methods: From 2008 to 2018, we performed 32 unilateral microsurgical breast reconstructions (mean patient age: $40.1 \pm 8.7$ years; range, $23-58$ years). As internal mammary vessels were exclusively used as recipients, they were dissected using a technique of minimally invasive video-assisted thoracoscopic surgery (VATS) developed in our hospital.

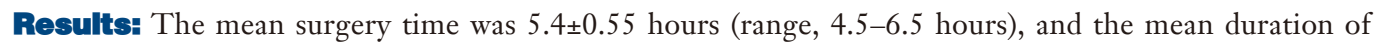
VATS dissection of internal mammary vessels was 20.6 \pm 2.9 minutes (range, 16-27 minutes). Of the specific complications associated with VATS, we only observed reductions in forced expiratory volume in the first second of $>15 \%$ in 3 patients $(9.4 \%), 10-15 \%$ in 8 patients $(25 \%)$, and $<10 \%$ in 21 patients $(65.63 \%)$. We did not have any cases of significant bleeding or postoperative infection in this series of patients. With regard to aesthetic complications, we observed 1 and 2 cases of total necrosis and partial necrosis of the deep inferior epigastric perforator (DIEP) flap, respectively and 2 cases of partial necrosis of supercharged transverse rectus abdominis muscle flap.

Conclusions: Endoscopic dissection of internal mammary vessels is a simple and feasible technique. When performed by experienced surgeons, it is a fast procedure that is associated with low rate of complications.

Keywords: Video-thoracoscopic surgery; internal mammary vessel dissection; DIEP-flap; breast reconstruction

Submitted Jan 15, 2020. Accepted for publication Jun 16, 2020.

doi: $10.21037 /$ gs-20-104

View this article at: http://dx.doi.org/10.21037/gs-20-104

\section{Introduction}

Over the last 2 decades, internal mammary vessels have been shown to be the best recipients for free flap breast reconstruction (1-4) due to the following reasons: (I) sufficient diameter, (II) proximity to site of anastomosis, (III) sufficient length for flap remodeling, and (IV) remoteness from the local pathological process (5). However, these vessels have the notable drawback of non-accessibility, which, in some cases, outweighs all their advantages. The internal mammary vessels are anatomic structures located inside the thoracic cavity, and this means that, to harvest them, rib resection has to be performed. This can lead to complications such as postoperative pain, tenderness, and contour deformity $(6,7)$.

To overcome this drawback, investigators proposed 
internal mammary vessel dissection without rib resection through muscle fiber separation (8), partial rib resection (9), or use of perforators (10). These techniques are also associated with high rate of complications such as bleeding, intrathoracic structure damage, inadequate diameter, and lack of anatomical variability (11).

Considering our experience in internal mammary vessel dissection during VATS parasternal lymphadenectomy, we deemed it imperative to ask the following question: "what if we could circumvent the greatest drawback of internal mammary vessels and avoid traumatic and uncontrolled access to these vessels?"

The aim of this study was to develop a minimally invasive surgical technique for the dissection of internal mammary vessels as recipients for breast reconstruction.

We present the following article in accordance with the STROBE reporting checklist. Available at http://dx.doi. org/10.21037/gs-20-104.

\section{Methods}

\section{Operative technique}

\section{Patients}

A retrospective analysis of prospectively recorded data of patients undergoing microsurgical breast reconstruction at the Clinical Oncological Center of Tatarstan was undertaken.

The Clinical Oncological Center of Tatarstan has a multidisciplinary breast cancer department where all types of breast cancer surgeries can be performed by the same surgical team. From 2008 to 2018, we performed 32 unilateral microsurgical breast reconstructions. Of these, 26 were immediate reconstructions and 6 were delayed reconstructions.

The patients were enrolled from the operation database of the clinic (Medical Informative System BARS, License No. 1660120850, Kazan, Russia). The inclusion criteria were as follows: immediate or delayed breast reconstruction, autologous breast reconstruction, performance of microsurgical anastomosis during breast reconstruction. Existing data for at least 3 months of follow-up was required for inclusion.

The indications for microsurgical breast reconstruction are as follows: age of $18-60$ years and the feasibility of and indications for mastectomy (TNM stages I to III and patient election). The contraindications for microsurgical breast reconstruction were as follows: TNM stage IV, neoadjuvant chemotherapy, severe general condition of the patient (American Society of Anesthesiologists class >3), previous abdominal surgery, severe concomitant disease affecting vessels (e.g., diabetes and connective tissue disorders), and previous bypass heart surgery (in the case of left-side reconstruction). A specific contraindication for video-assisted thoracoscopic surgery (VATS) is respiratory insufficiency (moderate/severe), which is defined as forced expiratory volume in $1^{\text {st }}$ second (FEV1, determined by spirometry) $<80 \%$. None of the patients had pre- or postoperative radiotherapy.

Patient characteristics are summarized in Table 1.

As internal mammary vessels were exclusively used as recipients, they were dissected using a technique of minimally invasive VATS developed in our hospital (12).

In the preoperative period, we performed standard evaluations including assessment of general health status, electrocardiography, mammography, ultrasonographic imaging of the contralateral breast and regional lymph nodes, blood analysis, and urinalysis as well as chest radiography and spirometry with further consultations with internists and anesthesiologists.

\section{Equipment}

For visualization, we used a VATS set manufactured by Störz (Karl Storz, Culver City, CA, USA) consisting of a large screen, an endoscopic camera, 2 video monitors, a xenon light source, a video registration and reproduction system, and a video recorder. The thoracoscope had the following characteristics: diameter of $10 \mathrm{~mm}$ and $0^{\circ}$ with a $5 \mathrm{~mm}$ biopsy channel ("view-only" thoracoscope). Other instruments that were used that are worthy of mention include trocars, thoracoports $(5 \mathrm{~mm}$ in diameter), electrocautery devices (bipolar and monopolar), endoscissors, and endostaplers (Endomedium, Kazan, Russia).

\section{Technique of video-thoracoscopic dissection of internal mammary vessels}

After the administration of general anesthesia, intubation is performed using a Carlens double-lumen tube. A cuneiform pillow is placed under the ipsilateral hemithorax with its sharp side oriented toward the median line. Due to the placement of the pillow, the patient position changes from supine position to a $45^{\circ}$ lateral position and the intercostal spaces widen markedly, thereby increasing the ease of trocar introduction. After mastectomy is completed, the anesthesiologist "switches off" respiration in the ipsilateral 
Table 1 Baseline demographic and clinical characteristics of the patients

\begin{tabular}{|c|c|}
\hline Characteristics & Summary $(\mathrm{N}=32)$ \\
\hline \multicolumn{2}{|l|}{ Age (years) } \\
\hline Range & $23-58$ \\
\hline Mean \pm SD & $40.1 \pm 8.7$ \\
\hline \multicolumn{2}{|l|}{ FEV1 (\%) } \\
\hline Range & $80-96$ \\
\hline Mean \pm SD & $87.4 \pm 4.75$ \\
\hline \multicolumn{2}{|l|}{ BMI $\left(\mathrm{kg} / \mathrm{m}^{2}\right)$} \\
\hline Range & $22-35$ \\
\hline Mean \pm SD & $28.1 \pm 3.5$ \\
\hline \multicolumn{2}{|l|}{ TNM stage (N, \%) } \\
\hline 0 & $3(9.4)$ \\
\hline I & $16(50.0)$ \\
\hline II & $11(34.4)$ \\
\hline III & $2(6.3)$ \\
\hline \multicolumn{2}{|l|}{ Time of reconstruction $(\mathrm{N}, \%)$} \\
\hline Immediate & $26(81.3)$ \\
\hline Delayed & $6(18.8)$ \\
\hline \multicolumn{2}{|l|}{ Affected side (N, \%) } \\
\hline Left & $18(56.3)$ \\
\hline Right & $14(43.8)$ \\
\hline \multicolumn{2}{|l|}{ Axillary lymphadenectomy } \\
\hline Yes (N, \% of patients) & $32(100.0)$ \\
\hline No (N, \% of patients with positive nodes) & $9(28.1)$ \\
\hline \multicolumn{2}{|l|}{ Parasternal lymphadenectomy } \\
\hline Yes (N, \% of patients) & $32(100.0)$ \\
\hline No (N, \% of patients with positive nodes) & $2(6.3)$ \\
\hline \multicolumn{2}{|l|}{ Type of breast reconstruction (N, \%) } \\
\hline Supercharged TRAM flap & $12(37.5)$ \\
\hline Free TRAM flap & $2(6.3)$ \\
\hline DIEP flap & $18(56.3)$ \\
\hline
\end{tabular}

SD, standard deviation; FEV1, forced expiratory volume in the first second; BMI, body mass index; TNM, tumor-nodemetastasis; TRAM, transverse rectus abdominis muscle; DIEP, deep inferior epigastric perforator. lung. Trocars are then inserted into the $5^{\text {th }}$ intercostal space along the medial clavicular line, into the $4^{\text {th }}$ intercostal space along the anterior axillary line, and into the $5^{\text {th }}$ intercostal space along the medial axillary line (Figure $1 A$ ). Gas insufflation is not necessary as, unlike the abdominal cavity, the thoracic cavity is a natural optical cavity.

Surgery is performed under conditions of open pneumothorax, and if adhesions are present, they are dissected using endoscissors with further coagulation. The lung collapses after 2-5 minutes. After examination of the pleural cavity, the parietal pleura is dissected parallel to the vessels from the $4^{\text {th }}$ intercostal space to the $1^{\text {st }}$ intercostal space (Figure 1B). Two clips are placed on the distal end of the vessels, and 1 clip is placed on the proximal end of the vessels (Figure 1C). The vessels are dissected upwards (en bloc with surrounding internal mammary lymph nodes) up to the $2^{\text {nd }}$ intercostal space (Figure 1D). Muscle fibers are separated from the outside (Figure 1E), and the distal ends of the vessels with the lymph nodes are extracted from the chest cavity (Figure $1 F$ ). The lymph nodes are sent to the laboratory for pathological examination (i.e., for disease staging), and the vessels are prepared for microsurgical anastomosis (Figure 1G, Video 1). After vessel extraction, thorough check of hemostasis and final lavage with saline are performed, a drainage tube is inserted into the pleural cavity, and the trocars are removed. The anesthesiologist then "switches on" the ipsilateral lung. The cuneiform pillow is removed, and flap harvesting is started.

Finally, microsurgical anastomosis is created between the internal mammary vessels and the donor vessels (with deep inferior epigastric vessels in the vast majority of cases) (Figure 1H, Video 1). The drainage tubes are removed on postoperative day 2 or 3 .

\section{Statistics}

Statistical analysis was performed with Epi $\operatorname{Info}^{\mathrm{TM}} 7.2$ (Atlanta, Georgia, USA). Means and SD, as well as frequencies of data of interest were calculated.

The study was approved by the Ethics Committee of Kazan State Medical Academy (ID: Number 10, from 11.11.2008) and was conducted in accordance with the principles of the Declaration of Helsinki and its amendments. All the patients provided written informed 

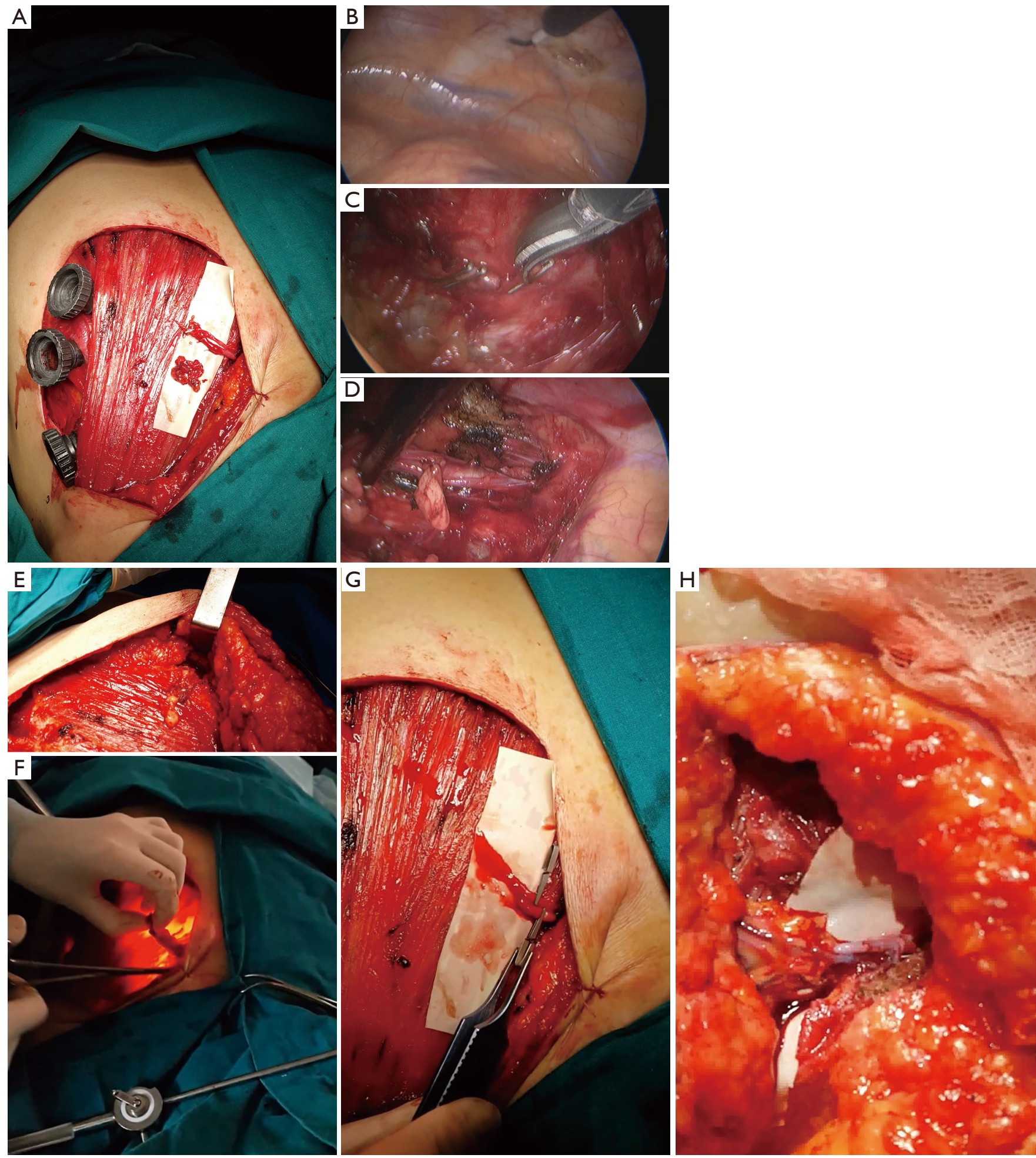

Figure 1 Stages of of internal mammary vessel endoscopic dissection. (A) Thoracoport positions after mastectomy. Left side. (B) Beginning of dissection from $4^{\text {th }}$ intercostal space upwards. (C) Clips placed at the level of the $4^{\text {th }}$ intercostal space (2 at the proximal end and 1 at the distal end). (D) Dissected vascular pedicle with lymph nodes en bloc at the level of $2^{\text {nd }}$ intercostal space. (E) Separation of muscle fibers at the level of $2^{\text {nd }}$ intercostal space. (F) Recipient vessel preparation. (G) Anastomosis with deep inferior epigastric perforators. (H) Anastomosis between deep inferior epigastric and internal mammary vessels. 
Table 2 Main characteristics of surgical treatment and postoperative period

\begin{tabular}{|c|c|c|c|}
\hline Characteristics & Summary $(\mathrm{N}=32)$ & Partial ( $\leq 30 \%$ of surface) & Total ( $\geq 60 \%$ of surface) \\
\hline Range & $4.5-6.5$ & - & - \\
\hline Mean \pm SD & $5.4 \pm 0.55$ & - & - \\
\hline \multicolumn{4}{|c|}{$\begin{array}{l}\text { Duration of videothoracoscopic dissection of internal } \\
\text { mammary vessels (minutes) }\end{array}$} \\
\hline Mean \pm SD & $20.6 \pm 2.9$ & - & - \\
\hline \multicolumn{4}{|c|}{ Duration of postoperative hospitalization (days) } \\
\hline Range & $3-7$ & - & - \\
\hline FEV1 reduction $10-15 \%$ & $8(25.0)$ & - & - \\
\hline FEV1 reduction $<10 \%$ & $21(65.6)$ & - & - \\
\hline \multicolumn{4}{|c|}{ Flap complications: skin flap necrosis (N, \%) } \\
\hline Supercharged TRAM flap $(\mathrm{N}=12)$ & - & $2(16.7)$ & 0 \\
\hline Free TRAM flap $(\mathrm{N}=2)$ & - & 0 & 0 \\
\hline DIEP flap $(\mathrm{N}=18)$ & - & $2(11.1)$ & $1(5.6)$ \\
\hline
\end{tabular}

SD, standard deviation; VATS, video-assisted thoracoscopic surgery; FEV1, forced expiratory volume in the first second; TRAM, transverse rectus abdominis muscle; DIEP, deep inferior epigastric perforator.

consent before participating in the study.

\section{Results}

The details of the surgical treatment are presented in Table 2 .

There was 1 case of total necrosis of deep inferior epigastric perforator (DIEP) flap at the beginning of the learning curve when we had not yet quite mastered the microsurgical technique.

The results of DIEP flap reconstruction (at 2 weeks after operation) in a 46-year-old patient are shown in Figure 2.

In the first 2 postoperative days, before the removal of the drainage tube from the thoracic cavity, we subjectively assessed the state of the patient based on the chest tube with the aid of a simple questionnaire developed by our team. The assessment was interpreted as follows: 1 stands for feeling of complete wellness, 2 for mild discomfort, 3 for moderate discomfort, 4 for severe discomfort, and 5 for pain. Six patients $(7.2 \%)$ complained of pain, 8 (9.6\%) of severe discomfort, 11 (13.25\%) of moderate discomfort, and $17(20.5 \%)$ of mild discomfort.

The median of follow-up time was 27 (interquartile range, 14-62) months.

\section{Discussion}

Endoscopic dissection of internal thoracic vessels is not a new procedure as it is widely performed worldwide for bypass surgeries. As such, the advantages and disadvantages of this procedure as well as the possible postoperative complications have been carefully studied $(12,13)$.

Our technique of endoscopic dissection of internal thoracic vessels is performed using the VATS parasternal lymphadenectomy procedure developed at the Clinical Oncological Center of Tatarstan in 1995 (14). In the "pre-sentinel node" epoch, this procedure was routinely performed along with axillary lymphadenectomy in patients with central-medial breast cancer (15). When this 

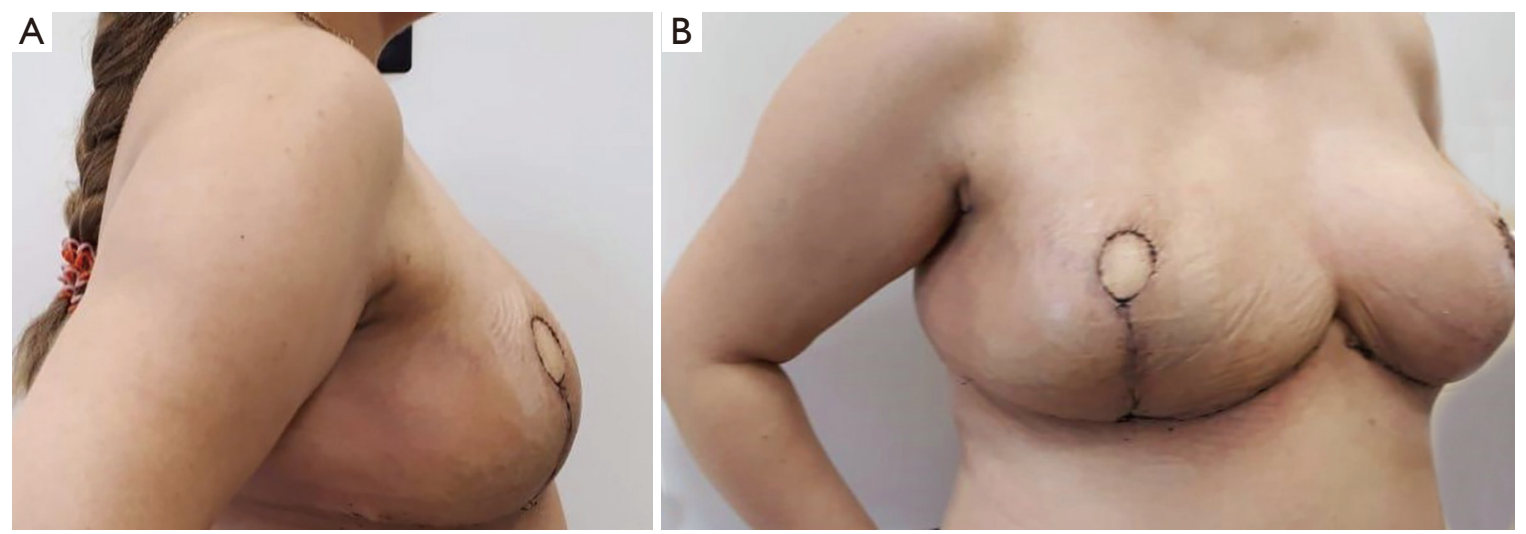

Figure 2 Immediate reconstruction of the right breast with deep inferior epigastric perforator flap. Simultaneous mastopexy of the left breast. Two weeks after surgery. (A) Right oblique lateral view. (B) Right lateral view.

procedure was performed on 1,674 patients in 2010, it was found that the procedure is associated with minimal complications. The highest rate of complications (including worsening of spirometry curves, skin necrosis, and flap necrosis) was observed in the patient group that underwent pedicled TRAM flap reconstruction. The authors explained that this was due to reduced blood supply to the TRAM flap when harvesting the internal mammary vessels. The postoperative decline in FEV1 was explained by the sacrifice of the abdominal muscles and further reconstruction of the abdominal wall under tension (16).

Since 2000, VATS has been included in the residency program of oncological surgeons at the breast cancer department. In the first 2 years of training, young doctors perform the procedure at an average time of 45 minutes, and after 3 years of regularly performing this procedure, the average time of the procedure decreases to 20-30 minutes.

In this series, the average duration of VATS dissection of internal mammary vessels was $20.6 \pm 2.9$ minutes, which is comparable to the duration of internal mammary vessel exposure using the rib-sparing method reported in the study by Kim et al. (17).

Moreover, for many breast surgeons in many countries whose basic specialty is general surgery, this surgery should be relatively easy to perform since the skills are the same as those of laparoscopic surgery.

Finally, this procedure can be performed in cases where access to the $2^{\text {nd }}$ intercostal space is difficult due to the small (periareolar access) or remote (inframammary access) incision for radical mastectomy.

Endoscopic dissection of internal mammary vessels has drawbacks such as need for special training, unsuitability for patients with respiratory insufficiency, and unfeasibility of using left-side vessels in patients with coronary heart disease who may need bypass surgery.

\section{Conclusions}

Endoscopic dissection of internal mammary vessels is a simple and feasible technique with an acceptable learning curve for surgeons, and when performed by experienced surgeons, it is a rather fast procedure with a low rate of complications.

\section{Acknowledgments}

Funding: None.

\section{Footnote}

Reporting Checklist: The authors have completed the STROBE reporting checklist. Available at http://dx.doi. org/10.21037/gs-20-104

Data Sharing Statement: Available at http://dx.doi. org/10.21037/gs-20-104

Peer Review File: Available at http://dx.doi.org/10.21037/gs20-104

Conflicts of Interest: All authors have completed the ICMJE uniform disclosure form (available at http://dx.doi. org/10.21037/gs-20-104). The authors have no conflict of interest to declare. 
Ethical Statement: The authors are accountable for all aspects of the work in ensuring that questions related to the accuracy or integrity of any part of the work are appropriately investigated and resolved. The study was approved by the Ethics Committee of Kazan State Medical Academy (ID: Number 10, from 11.11.2008) and was conducted in accordance with the principles of the Declaration of Helsinki and its amendments (as revised in 2013). All the patients provided written informed consent before participating in the study.

Open Access Statement: This is an Open Access article distributed in accordance with the Creative Commons Attribution-NonCommercial-NoDerivs 4.0 International License (CC BY-NC-ND 4.0), which permits the noncommercial replication and distribution of the article with the strict proviso that no changes or edits are made and the original work is properly cited (including links to both the formal publication through the relevant DOI and the license). See: https://creativecommons.org/licenses/by-nc-nd/4.0/.

\section{References}

1. O'Neill AC, Hayward V, Zhong T, et al. Usability of the internal mammary recipient vessels in microvascular breast reconstruction. J Plast Reconstr Aesthet Surg 2016;69:907-11.

2. Saour S, Libondi G, Ramakrishnan V. Microsurgical refinements with the use of internal mammary (IM) perforators as recipient vessels in transverse upper gracilis (TUG) autologous breast reconstruction. Gland Surg 2017;6:375-9.

3. Clark CP 3rd, Rohrich RJ, Copit S, et al. An anatomic study of the internal mammary veins: clinical implications for free-tissue-transfer breast reconstruction. Plast Reconstr Surg 1997;99:400-4.

4. Haddock NT, Teotia SS. Five Steps to Internal Mammary Vessel Preparation in Less than 15 Minutes. Plast Reconstr Surg 2017;140:884-6.

5. Henry FP, Leckenby JI, Butler DP, et al. An algorithm to guide recipient vessel selection in cases of free functional muscle transfer for facial reanimation. Arch Plast Surg 2014;41:716-21.

6. Majumder S, Batchelor AG. Internal mammary vessels as recipients for free TRAM breast reconstruction: aesthetic and functional considerations. Br J Plast Surg 1999;52:286-9.

7. Parrett BM, Caterson SA, Tobias AM, et al. The rib- sparing technique for internal mammary vessel exposure in microsurgical breast reconstruction. Ann Plast Surg 2008;60:241-3.

8. Zhang Q, Xiao Q, Guo R, et al. Applications of rib sparing technique in internal mammary vessels exposure of abdominal free flap breast reconstructions: a 12year single-center experience of 215 cases. Gland Surg 2019;8:477-85.

9. Malata CM, Rabey NG. Decision Making in DoublePedicled DIEP and SIEA Abdominal Free Flap Breast Reconstructions: An Algorithmic Approach and Comprehensive Classification. Front Surg 2015;2:49.

10. Vollbach FH, Heitmann CD, Fansa H. An Appraisal of Internal Mammary Artery Perforators as Recipient Vessels in Microvascular Breast Reconstruction-An Analysis of 515 Consecutive Cases. Plast Reconstr Surg Glob Open 2016;4:e1144.

11. Hamdi M, Blondeel P, Van Landuyt K, et al. Algorithm in choosing recipient vessels for perforator free flap in breast reconstruction: the role of the internal mammary perforators. Br J Plast Surg 2004;57:258-65.

12. Yim D, Wong WYE, Fan KS, et al. Internal mammary harvesting: Techniques and evidence from the literature. J Card Surg 2020;35:860-7.

13. Brancaccio G, Prifti E, Cricco AM, et al. Chylothorax: a complication after internal thoracic artery harvesting. Ital Heart J 2001;2:559-62.

14. Dmitriev EG, Sigal EI. Thoracoscopic surgery in the management of mediastinal masses. Indications, complications, limitations. Surg Endosc 1996;10:718-20.

15. Ismagilov AKh, Sigal EI, Gimranov AM. Parasternal lymph node excision in breast cancer. Khirurgiia (Mosk) 2001;(10):11-6.

16. Vanesyan AS. The investigation of the influence of the breast cancer on the quality of life of patients with centralmedial breast cancer. Creative Surgery and Oncology 2011;4:42-7.

17. Kim H, Mun GH. Reply: rib-sparing and internal mammary artery-preserving microsurgical breast reconstruction with the free DIEP flap. Plast Reconstr Surg 2013;132:870e-1e.

Cite this article as: Ismagilov A, Vanesyan A, Ovchinnikova I, Khamitov A, Basiashvili G, Zinchenko S. New technique of dissection of internal mammary vessels for breast reconstruction. Gland Surg 2020;9(4):886-892. doi: 10.21037/gs20-104 